\title{
STUDI PEMAHAMAN VISI MISI INSTITUSI DAN PENELURUSAN KESESUAIAN KOMPETENSI PADA ALUMNI JURUSAN KEPERAWATAN GIGI POLTEKKES \\ KEMENKES SEMARANG \\ TAHUN 2010 - 2016
}

Sulur Joyo Sukendro ${ }^{1}$, Sariyem $^{2}$, Endah Aryati Eko Ningtyas ${ }^{3}$

\begin{abstract}
ABSTRAK
PoliteknikKesehatanKemenkes Semarang (Poltekkes Semarang)adalah unit pelaksana teknis Kementerian Kesehatan RI yang berada di bawah dan bertanggungjawab kepada Kepala Badan Pengembangan dan Pemberdayaan Sumber Daya Manusia (PPSDM) Kesehatan. Jurusan Keperawaan Gigi Semarang mempunyai program studi D III Keperawatan Gigi dan program studi D IV Keperawatan Gigi danmenghasilkantenagakesehatan yang berdayasaingtinggi. Dokumentasiuntukmelacak alumni Jurusan Keperawatan Gigi Poltekkes Semarang belumdilaksanakansecara optimal. Hal ini terjadi karena pelacakan alumni membutuhkan sumberdaya dan sumberdana yang cukup besar, oleh sebab itu perlu dilakukan kegiatan pelacakan alumni dan pemahaman visi misi institusi dan kesesuaian kompetensi pada alumni.

Tujuandaripenelitian iniadalahmemetakanposisilulusandalam dunia kerja, proses dan riwayat pekerjaan, pemahaman visi dan misi lembaga, peta kesenjangankompetensilulusandengantuntutan dunia kerja dan dayaserap, sertakesesuaiankompetensibidangilmudenganbidangpekerjaan. Tahapankegiatan yang dilakukandalampelaksanaan pemetaan karakterisik alumni meliputi 4 (empat) tahapyaitutahappersiapan, tahappelaksanaan, tahapanalisa dan tahapevaluasi/tindaklanjut.

Metode yang digunakandalampelacakanadalahmelaluikuesioneronlineberbantu SMS Gateway, jejaring media social (Whatsapp Group, Facebook Group, BBM group, Line, email). Diharapkanseorang alumni perwakilanangkatan 2010-2016 sebagaipioneer yang akanmengajaktemannyadalam group untukikutberpartisipasi. Pemberian reward berupapaket pulsadigunakanuntukmeningkatkanresponse rate. Data yang didapatkanakandianalisasesuaidenganindikator yang telahditentukansehinggadiharapkanmampumenghasilkanlaporan dan kesimpulanterkait data lulusan.

Hasil penelitian yaitu Visi Misi Jurusan Keperawatan Gigi Poltekkes Kemenkes Semarang perlu diberikan pemahaman kepada alumni pada kegiatan-kegiatan lembaga atau pada saat seminar yang dihadiri alumni. Rata-rata lama waktu tunggu alumni dalam mendapatkan pekerjaan pertama pada tahun 2010-2016 yaitu kurang dari 3 bulan dengan persentase sebesar $59 \%$ dan yang menunggu $>12$ bulan dengan persentase sebesar $1,9 \%$. Jenis pekerjaan alumni yang sesuai yaitu $85 \%$ bekerja terapis gigi dan mulut. Tempat kerja alumni 52\% di Instansi pemerintah dan rumah sakit, 29\% bekerja di Klinik Gigi Bersama atau Pribadi. Rata-rata penghasilan atau gaji alumni yaitu 78,7\% masih dalam kategori rendah dan sangat rendah.

Kesimpulanpenelitian ini adalah perlu lembaga memperhatikan masukan alumni terhadap kemampuan pada saat lulus maupun upaya peningkatan kemampuan sesuai kebutuhan di lapangan kerja.
\end{abstract}

Kata kunci: Penelusuran, Alumni, Jurusan Keperawatan Gigi 


\begin{abstract}
The Health Polytechnic of the Ministry of Health Semarang (Poltekkes Semarang) is the technical implementation unit of the Indonesian Ministry of Health which is under and responsible to the Head of the Human Resources Development and Empowerment Agency (PPSDM) Health. The Department of Dental Nursing Semarang has a D III Dental Nursing study program and a D IV Dental Nursing study program and produces highly competitive health personnel. Documentation to track alumni of the Department of Dental Nursing, Poltekkes Semarang has not been implemented optimally. This happens because tracking alumni requires considerable resources and resources, therefore it is necessary to carry out alumni tracking activities and an understanding of the vision and mission of the institution and the suitability of competencies for alumni.

The purpose of this research is to map the position of graduates in the world of work, work processes and history, understanding the vision and mission of the institution, map the competency gap of graduates with the demands of the world of work and absorption, and the suitability of competence in the field of science and the field of work. The stages of activities carried out in the implementation of the alumni characteristic mapping include 4 (four) stages, namely the preparation stage, the implementation stage, the analysis stage and the evaluation / follow-up stage.

The method used in tracking is through an online questionnaire with the help of SMS Gateway, social media networks (Whatsapp Group, Facebook Group, BBM group, Line, email). It is hoped that an alumni representative of the 2010-2016 class will be a pioneer who will invite his friends in the group to participate. Rewarding in the form of pulse packages is used to increase the response rate. The data obtained will be analyzed according to predetermined indicators so that it is expected to be able to produce reports and conclusions related to graduate data.

The results of the study, namely the Vision and Mission of the Department of Dental Nursing, Poltekkes of the Ministry of Health, Semarang, need to be given an understanding to alumni at institutional activities or at seminars attended by alumni. The average length of waiting time for alumni to get their first job in 2010-2016 was less than 3 months with a percentage of 59\% and those who waited $>12$ months with a percentage of $1.9 \%$. The appropriate type of work for alumni is that $85 \%$ work as dental and oral therapists. Workplaces of alumni $52 \%$ in government agencies and hospitals, 29\% work in Joint or Private Dental Clinics. The average income or salary of alumni, namely $78.7 \%$, is still in the low and very low category.

The conclusion of this study is that the institution needs to pay attention to alumni input on the ability at the time of graduation as well as efforts to increase abilities according to the needs in the work field.
\end{abstract}

Keywords: Searching, Alumni, Department of Dental Nursing

1,2,3 :DosenJurusanKeperawatan Gigi PoliteknikKesehatanKemenkes Semarang 


\section{PENDAHULUAN}

Politeknik Kesehatan Kemenkes Semarang didirikan berdasarkan Surat Keputusan Menteri Kesehatan dan Kesejahteraan Sosial RI Nomor 298 / MENKES-KESOS / SK / IV/ 2001 tanggal 16 April 2001 dan terakhir diubah dengan Peraturan Menteri Kesehatan RI Nomor 1988/Menkes/Per/IX/2011 tanggal 27 September 2011 tentang Perubahan atas Peraturan Menteri Kesehatan RI Nomor 890 / MENKES/ VIII/ 2007 tanggal 2 Agustus 2007 tentang Organisasi dan Tata Kerja Politeknik Kesehatan. Berdasar surat dari Sekretariat Jenderal Kementerian Kesehatan RI Nomor TU 05.02/II/II/1535/2010,tanggal 18 Pebruari 2010 tentang Perubahan Nomenklatur Departemen Kesehatan RI menjadi Kementerian Kesehatan RI, maka Politeknik Kesehatan Kemenkes Semarang berubah menjadi Poltekkes Kemenkes Semarang.

Dalam perkembangannya sejak tahun 2005 Poltekkes KemenkesSemarang membuka program studi baru dan kelas unggulan (terdiri dari Program Studi Diploma III Keperawatan, Kebidanan, Teknik Radiodiagnostik dan Radioterapi, dan Kesehatan Gigi) dan program studi baru meliputi Program Studi Diploma IV Teknik Radiologi Semarang, Diploma IV Keperawatan Klinik Semarang meliputi:
Kemahiran Medikal Bedah, Kemahiran Kegawat Daruratan dan Kemahiran Kardiovaskuler. Selanjutnya berturut-turut dibuka Program Studi Diploma IV Bidan Pendidik Semarang, Diploma IV Gizi Semarang, Diploma IV Kesehatan Lingkungan Purwokerto, Diploma IV Kesehatan Gigi Komunitas Semarang, Diploma III Kebidanan Purwokerto, Diploma III Teknik Radiodiagnostik dan Radioterapi Purwokerto dan Diploma IV Kebidanan Komunitas Magelang. Pada tahun Akademik 2009/2010 dibuka Program Studi Diploma IV Keperawatan Jiwa Magelang dan Jurusan Analis Kesehatan. Pada Tahun Akademik 2012/2013 dibuka Program Studi D III Kebidanan Blora. Selanjutnya pada tahun Akademik 2013/2014 dibuka program pendidikan D III Rekam Medis dan Informasi Kesehatan dan pada tahun Akademik 2014/2015 mulai diselenggarakan program pendidikan yaitu Program Pascasarjana Program Magister Terapan Kesehatan meliputi Program Studi Kebidanan,Program Studi Keperawatan dan Program Studi Imaging Diagnostik berdasarkan Surat Keputusan Menteri Pendidikan dan Kebudayaan RI No.520/E/O/2014 tanggal 16 Oktober 2014.

Dalam pencapaian Misi Jurusan Keperawatan Gigi ditetapkan beberapa Sasaran Mutu diantaranya adalah yang 
berhubungan dengan kualitas lulusan yaitu $80 \%$ lulusan bekerja dalam 6 (enam) bulan pertama.SasaranMutuinidipantau oleh Unit PengembanganKarirPoltekkesKemenkesSema rang dibantu bagian Kemahasisswaan di tingkat Jurusan. Kegiatan yang telahdilakukanadalahPromosiLulusan,

Campus On Hiring/recruitmen, Job Fair, Pembuatan $\mathrm{MoU}$

PendayagunaanLulusandenganRumahSakit

Nasional dan International meningkatkanketrampilanlulusanbaikdalambe ntuksertifikatkeahlianataupunketrampilanberb ahasaInggrissertaketrampilanmenulis $\mathrm{CV}$ sertamelakukanwawancarakerja.

Kegiatan pelacakan alumni di Jurusan Keperawatan Gigi

PoltekkesKemenkesSemarang

selamainidilaksanakansecara manual maupun lewat pos dengan segala keterbatasannya. Padatahun2016 melalui kegiatan seminar telahdilaksanakan survey pelacakan alumni menggunakan kuesioner yang diisi oleh 90 sampel alumni dariangkatan 2004-2014. Jumlahinimasihsangatsedikit yang terlacakdibandingandengan alumni yang berjumlahlebihdari50 mahasiswa setiaptahun. Sedangkankegiatanpeningkatkankesiapan dan kemampuan alumni dalambersaing di dunia kerjatelahdilaksanakandalambentukpenyeleng garaan seminar dan pelatihantespotensiakademiksertaoncampus recruitmendenganpihakketiga.

Namunintensitas

dan

frekuensikegiatanmasihsedikit.

Berdasarkanlatarbelakang di atas, maka pada

tahun

2017akandilaksanakankegiatanpelacakan

alumni dan pemahaman visi misi institusi dan penelurusan kesesuaian kompetensi pada alumni Jurusan Keperawatan Gigi lulusantahun2010 - 2016berjumlah 820 mahasiswa.

Berdasarkan Laporan Wisuda Periode 2010-2016 Politeknik Kesehatan Semarang dimana telah dilakukan 7 wisuda yang melibatkan wisuda mahasiswa Jurusan Keperawatan Gigi. Data lulusan jumlah lulusan D III dan D IV sejumlah 820 dengan perincian sbb:

Tabel 1 Jumlah lulusan Jurusan

Keperawatan Gigi 2010 - 2016

\begin{tabular}{|c|c|c|c|}
\hline No & Tahun & $\begin{array}{c}\text { D III } \\
\text { Keperawatan } \\
\text { Gigi }\end{array}$ & $\begin{array}{c}\text { D IV } \\
\text { Keperawatan } \\
\text { Gigi }\end{array}$ \\
\hline 1 & 2010 & 112 & 10 \\
\hline 2 & 2011 & 83 & 24 \\
\hline 3 & 2012 & 57 & 16 \\
\hline 4 & 2013 & 177 & 23 \\
\hline 5 & 2014 & 83 & 2 \\
\hline 6 & 2015 & 60 & 37 \\
\hline 7 & 2016 & 99 & 37 \\
\hline & Jumlah & 671 & 149 \\
\hline
\end{tabular}

Mayoritas lulusan Poltekkes Kemenkes Semarang adalah perempuan. Mayoritas mahasiswa berasal dari semua kabupaten/kota dari Jawa Tengah dan DIY dan beberapa mahasiswa berasal dari luar 
Jawa. Alumni angkatan 2010 - 2016 berdasarkan pelacakan yang telah dilakukan Program Studi telah bekerja lebih dari $90 \%$ baik yang bekerja di Rumah Sakit Negeri, Nasional, bekerja di klinik kesehatan ataupun sebagai dosen. Semua alumni telah bekerja sesuai dengan kompetensi. Data yang di dapat memang sudah cukup tinggi porsentase nya hanya data yang didapat masih sangat minim hanya lokasi bekerja tetapi informasi lain yang dibutuhkan untuk pengembangan kurikulum dan kebutuhan pengguna masih belum di dapat. Diharapkan dengan adanya penelitian berupa pelacakan alumnilulusan tahun 2010 - 2016 dapatdilengkapi dan dianalisis secara lebih kompleks.

Pelaporan data lulusan Jurusan Keperawatan Gigi Poltekkes Kemenkes Semarang yang telah dilakukar ${ }_{4}$ dan dilaporkan ke Unit Karir Poltekkes Semarang adalah sebagai berikut :

Tabel 2.Rekapitulasi laporan unit Karier sampai tahun akademik 2014/2015semester gasal

\begin{tabular}{|l|r|r|r|r|}
\hline Prodi & TS-4 & TS-3 & TS-2 & TS-1 \\
2010 & 2011 & 2012 & 2013 \\
\hline $\begin{array}{l}\text { D III } \\
\text { Keper } \\
\text { awata } \\
\text { n Gigi }\end{array}$ & 25 & 19 & 24 & 24 \\
\hline
\end{tabular}

Tujuan dari pelacakan alumni adalah untuk memetakan kegiatan lulusan, masa tunggu kerja, penyerapan, proses, dan posisi lulusan dalam dunia kerja, kesesuaian bidang kerja dengan bidang studi, kesenjangan kompetensi lulusan, relevansi kurikulum dengan kebutuhan dunia kerja, daya serap lulusan dan kesesuaian kompetensi dengan kebutuhan pengguna lulusan dalam dunia kerja serta mengetahui perkembangan kompetensi yang dibutuhkan oleh pengguna lulusan serta masukan dari para lulusan untuk pengembangan kurikulum dan kualitas pembelajaran.

Hasil dari pelacakan alumni akan dijadikan sebagai dasar dalam pengembangan dan penyempurnaan program pelaksanaan proses pendidikan seperti perbaikan kompetensi dan relevansi kurikulum dengan pasar dunia kerja, peningkatan proses pembelajaran, dan proses akreditasi maupun sertifikasi, serta peningkatan kinerja pengelola institusi. Sehingga secara bertahap dapat meningkatkan kepuasan pengguna lulusan yang hal ini diharapkan akan dapat meningkatkan daya serap penggunaan lulusan dan memperpendek waktu tunggu lulusan dalam mendapatkan pekerjaan. Serta membantu program pemerintah dalam rangka memetakan dan menyelaraskan kebutuhan dunia kerja dengan kompetensi yang diperoleh di perguruan tinggi dan meningkatkan daya saing bangsa menyongsong Program Masyarakat Ekonomi ASEAN (MEA).

Bagian Kemahasiswaan Jurusan 
Keperawatan Gigi telah melakukan penelusuran alumni dengan cara berkoordinasi dengan Ikatan Alumni Jurusan Keperawatan Gigi Poltekkes Kemenkes Semarang. Masing-masing tingkatan dengan kreatifitas cara masing-masing untuk melacak alumni, diantaranya dengan mengirimkan kuesionair secara manual (pos) ke alamat orang tua, lewat email berdasarkan data dari buku wisuda, mengirim SMS, menelpon langsung serta dengan bantuan dari Ikatan alumni di masing-masing Prodi. Hasil pelacakan adalah mayoritas alumni telah bekerja di RS negri ataupun swasta ataupun di puskesmas dan klinik.

Pelacakan alumni juga dilakukan melalui kuesionair yang dikembangkan bagian kemahasiswaan Poltekkes Kemenkes Semarang dan dikirimkan kepada institusi (stake holder) yang mendayagunakan lulusan Poltekkes Kemenkes Semarang. Kuesionair berisi tentang bagaimana kepuasan stake holder terhadap kinerja alumni Poltekkes Kemenkes Semarang. Data yang didapat sampai tahun 2015 di ketahui bahwa mayoritas stake holder $(92 \%)$ merasa puas dengan kinerja lulusan dari sisi ketrampilan, kerja sama team dan managerial.

Pelacakan alumni akan dilakukan secara on line, apalagi di Poltekkes Kemenkes Semarang telah mempunyai sitem IT yang sangat baik.Penerapkan beberapa sistem secara on line diantaranya adalah Sipenmaru On-line, library on line, Simadu (SistemInformasimanagemenAkademikTerp adu)

diantaranyaberisiPengisianKartuRencanaStu di, InformasiKartu Hasil Studi, Transkripakademik, Registrasi dan Herregistrasi on line sertapengelolaankarir dan alumni secara on line.

Metode pelacakan alumni yang telah dilakukan oleh bagian Kemahasiswa Jurusan Keperawatan Gigi belum bisa ideal dikarenakan keterbatasan biaya dan konsep yang belum terorganisir secara sensal dan ditemukan beberapa kendala dalam pelaksanaannya diantaranya:

1. Metode pelacakan melalui pengiriman ke email terkendala karena banyak alamat email yang sudah expired (tidak digunakan lagi), sehingga beberapa email tidak terbalas.

2. Metode pelacakan melalui surat yang dikirim ke alamat orang tua menjadi tidak efektif dikarenakan alumni sudah tidak tinggal di rumah dan orang tua merasa kuesionair tidak penting sehingga tidak disampaikan ke alumni.

3. Pengiriman undangan untuk pengisian kuesioner online melalui SMS broadcast terkendala karena ada beberapa nomor handphone yang sudahtidak digunakan lagi atau tidak aktif. 
4. Masih melakukan proses pelacakan alumni secara individu karena kebutuhan yang mendesak misalnya untuk proses akreditasi dan juga beberapa instrument kuesioner yang sedikit berbeda atau bertambah.

Sampai dengan tahun 2015, Bagian kemahasiswaan Jurusan di dukung Unit Pengembangan Karir Poltekkes Semarang telah melakukan kegiatan pelacakan alumni dalam bentuk melacak lokasi tempat kerja. Selain kegiatan pelacakan alumni, juga menyiapkan lulusan dengan memberikan pelatihan peningkatan soft skill yang digunakan sebagai bekal untuk mencari kerja. Peningkatan soft skill diantaranya adalah pelatihan pembuatan $\mathrm{CV}$ yang baik, pelatihan interview/wawancara kerja serta peningkatan kemampuan bahas english dan penguasaan IT.

Dengan adanya penelitian pelacakan alumni ini Jurusan Keperawatan Gigi Poltekkes Kemenkes Semarang akan mampu melaksanakan pelacakan alumni secara keseluruhan yang belum pernah dilaksanakan selama ini. Dengan pelaksanaan pelacakan alumni secara kompleks dengan pertanyaan standard maka akan banyak masukan bagi peningkatan Jurusan Keperawatan Gigi Poltekkes Kemenkes Semarang untuk memberikan bekal bagi lulusan.

\section{METODE PELACAKAN ALUMNI}

Desain penelitian adalah Observasional Study dengan rancangan Cross sectional dikarenakan semua variabel yang akan di teliti dilakukan pada saat yang bersamaan. Pengambilan data dilakukan dengan cara melakukan wawancara secara on line ataupun secara langsung face to face. Pengambilan data dilaksanakan dalam 4 tahapan yaitu tahap tahap persiapan, tahap pelaksanaan dan tahap analisa, serta tahap evaluasi/Rencana tindak lanjut.

Tahap Persiapan adalah tahapan awal dari pelaksanaan pelacakan alumni yang meliputi proses penentuan kuesionair yang akan dilakukan dalam kegiatan rapat dengan pengelola Jurusan, draft kuesionair yang diambil dari kuesioner pelacakan alumni dari Kemenristek Dikti disampaikan dalam pertemuan tingkat managemen dan ditentukan apakah akan menggunakan kuesionair atau ada penambahan pertanyaan. Setelah penentuan instrumen, langkah persiapan selanjutnya adalah mengumpulkan team peneliti, yang melibatkan 10 perwakilan tiap angkatan, serta pengurus alumni Jurusan Keperawatan Gigi untuk penentuan kontak semua alumni 2010 - 2016. Data berasal dari buku wisuda serta data yang ada pada masingmasing prodi serta group sosial media yang dilacak dengan menunjuk satu (1) perwakilan per kelas sebagai admin group.

Sosialisasi kegiatan pelacakan alumni 
akan dikerahkan dengan melalui pemasangan berita pada surat kabar dan sosial media. Pengumuman juga dilakukan pada website http://gigi.poltekkes-smg.ac.id. Penentuan pemberian hadiah undian berupa pengiriman pulsa bagi alumni yang mengisi kuesionair untuk lebih menarik minat alumni dalam memberikan partisipasi.

Tahap selanjutnya adalah Tahap Pelaksanaan yang terdiri dari pengiriman pemberitahuan atau udangan kepada lulusan tahun 2010 - 2016 melalui berbagai cara yaitu lewat group sosmed Whats App, BBM, Line serta email, SMS Broadcast ataupun menelpon secara langsung. Undangan hanya dikirimkan melalui email dan $\underset{9}{\text { SMS }}$ Broadcast.Undangan berisi permintaan bagi alumni untuk berpartsisipasi dalam kegiatan pelacakan alumni disertai dengan petunjuk cara pengisian. Alumni diharapkan masuk ke dalam sistem pelacakan alumni JKG Semarang. Bagian kemahasiswaan akan memantau terus menerus perkembangan setiap hari, berapa alumni yang sudah mengisi kuesionair. Team dari program studi juga akan ikut memantau dengan melakukan komunikasi secara intens dengan team peneliti. Perwakilan tiap angkatan akan melakukan reminder/pengingat kepada alumni yang sudah menerima undangan tetapi belum mengisi kuesionair. Kegiatan reminder akan dilakukan sebanyak 3 (tiga) kali sampai alumni bisa memberikan respon positif. Waktu yang akan digunakan untuk pengisian kuesionair adalah selama maksimal 2 (dua) bulan.

Data yang terkumpul akan di analisa yang terdiri dari pengolahan data, pembersihan data (cleansing data) apabila ditemukan data yang ganda. Kemudian dilakukan analisis data secara kuantitatif. Adapun bagan alur dibawah ini menggambarkan urutan penelitian pelacakan alumni Jurusan Keperawatan Gigi.

Populasi penelitianpelacakan alumni ini adalah seluruh alumni JKG Poltekkes Kemenkes Semarang tahun 2010 - 2016 berjumlah 820 mahasiswa. Sedangkan pelaksana penelitian adalah Bagian Kemahasiswaan Jurusan dibantu beberapa orang alumni.

Sampel adalah sebagian atau wakil populasi yang diteliti (Suharsimi Arikunto, 2006). Menurut Sugiyono (2009) sampel adalah bagian dari jumlah dan karakteristik yang dimiliki oleh populasi tersebut. Pengambilan sampel pada penelitian ini menurut Suharsimi Arikunto (2002), jika subjeknya kurang dari 100 orang sebaiknya diambil semuanya, jika subjeknya besar atau lebih dari 100 orang dapat diambil 10\%-15\% atau 20\%-25\% atau lebih. Teknik pengambilan sampel yang akan digunakan adalah $25 \%$ dari jumlah populasi. Sampel 
diambil dengan menggunakan teknik pengambilan sampel secara Proportionale Stratified Random Sampling yaitu teknik digunakan bila populasi mempunyai anggota atau unsur yang tidak homogen dan berstrata secara proposional (Sugiyono, 2009).

Jumlah populasi alumni JKG Poltekkes Kemenkes Semarang tahun 2010 2016 berjumlah 820 alumni, dari populasi tersebut diambil $25 \%$ dari populasi sehingga jumlah sampelnya adalah $25 \% \times 820$ alumni $=$ 205 alumni. Agar semua periode wisuda dapat terwakili, maka sampel diambil dari masingmasing periode tahun wisuda dengan proporsi sama. Berikut ini tabel jumlah sampel yang diambil:

Tabel 3.Jumlah lulusan JKG 2010 - 2016

\begin{tabular}{|c|c|c|c|}
\hline No & Tahun & Populasi & Sampel \\
\hline 1 & 2010 & 122 & 31 \\
\hline 2 & 2011 & 107 & 27 \\
\hline 3 & 2012 & 73 & 18 \\
\hline 4 & 2013 & 200 & 50 \\
\hline 5 & 2014 & 85 & 21 \\
\hline 6 & 2015 & 97 & 24 \\
\hline 7 & 2016 & 136 & 34 \\
\hline \multicolumn{5}{|c|}{ Jumlah } & 820 & 205 \\
\hline \multicolumn{4}{|c|}{ Metode pelacakan adalah dengan }
\end{tabular}

mengisi kuesionair secara lengap yang disiapkan secara on line. Diharapkan seluruh alumni yang terlacak dapat berpartisipasi dengan mengisi seluruh pertanyaan yang ada. Adapun metode pelacakan adalah dengan melalui beberapa cara:

1. Pemberian pemberitahuan/pengumunan tentang adanya kegiatan pelacakan alumni dengan cara mengisi kuesionair on line ditempuh dengan cara sbb:

a. Group Whats App: setiap kelas/angkatan mempunyai group WA, pendekatan kepada admin group akan dilakukan dengan bantuan perwakilan Program Studi

b. Line: medsos Line banyak digunakan oleh anak muda. Bagi alumni yang tidak terdaftar dalam group WA akan diberi undangan via Line

c. Pengumuman juga akan di berikan melalui email, alamat email alumni di dapatkan dari buku wisuda

d. Pengiriman via SMS juga akan dilakukan bagi alumni yang kemungkinan tidak tergabung dalam group WA, line atau email

e. Pengumuman via website http:///www.gigi.poltekkessmg.ac.id di menu tracer study

2. Metode pengisian kuesionair dilakukan dengan cara:

a. On line: pengisian kuesionair secara on line diharapkan yang paling banyak dilakukan karena metode ini adalah metode yang paling praktis dan effisien. Alumni mengakses website pelacakan alumni JKG dengan alamat $\underline{\text { http://bit.ly/lacak_alumni_JKG }}$ 
Pasword : jkgsemarang. Setiap alumni yang sudah mengisi akan mendapatkan paket pulsa agar menarik.

b. Wawancara: bagi alumni yang berada dekat dengan kampus dan bisa datang bisa mengisi kuesionair dengan metode wawancara yang akan dilakukan oleh team peneliti.

Instrumen kuesioner yang digunakan dalam kegiatan pelacakan alumni ini adalah kuesionair standard yang mengacu dari Kemenristek Dikti, ditambah kuesioner berkaitan pemahaman visi dan misi Jurusan Keperawatan Gigi. Kuesionair sangat lengkap menjangkau pertanyaan yang mendasar yang bisa mendapatkan informasi tentang lulusan mulai dari mahasiswa, setelah lulus, awal mencari pekerjaan sampai setelah alumni berganti pekerjaan untuk mendapatkan kesempatan kerja lebih baik. Informasiinformasi yang didapat dari kuesionair ini adalah:

1. Informasi mendapatkan pekerjaan.

2. Kesesuaian pekerjaan dengan bidang ilmu.

3. Masa tunggu kerja.

4. Informasi pekerjaan pertama dan pekerjaan saat ini

5. Transisi perpindahan pekerjaan
6. Pemahaman visi dan misi lembaga

7. Mismatch Horizontal (ketidaksesuaian bidang pekerjaan dengandisiplin ilmu) dan Mismatch Vertical (ketidaksesuaian tingkat pekerjaan dengan level kesarjanaan).

8. Kemampuan hardskill dan softskill.

9. Kepuasan lulusan terhadap pembelajaran

10. Saran masukan (feedback) terhadap peningkatan kualitas pembelajaran dan layanan di JKG Poltekkes Kemenkes Semarang.

Pertanyaan-pertanyaan pada kuesionair secara deskriptif dapat dijabarkan Sebagai berikut :

1) Identitas Lulusan
a. Nama alumni/lulusan
b. Jenis kelamin
c. Alamat terbaru
d. Email dan Telepon

2) Transisi ke Dunia Kerja
a. Kegiatan setelah lulus (bekerja, wirausaha, melanjutkan studi, tidak bekerja)

b. Waktu mulai mencari pekerjaan

c. Masa tunggu mendapatkan pekerjaan pertama

d. Jumlah instansi yang dituju untuk lamaran pekerjaan dan merespon 
e. Kesesuaian pekerjaan dengan tingkat pendidikan

f. Kemampuan hardskill dan softskill

3) Pemahaman Visi Misi lembaga / JKG

4) Pengalaman Akademik dan NonAkademik

a. Metode pembelajaran apa yang perlu ditingkatkan

b. Pengalaman organisasi

c. Keaktifan di organisasi

5) Kompetensi

a. Kompetensi yang sesuai antara bidang ilmu dan pekerjaan

b. Kompetensi yang tidak sesuai atau yang belum ada dan dibutuhkan untuk mendapatkan pekerjaan

6) Kualitas Pembelajaran

a. Matakuliah yang perlu ditekankan atau diadakan untuk menungjang kompetensi

b. Kemampuan hardskill dan softskill yang harus diajarkan di pembelajaran

c. Keahlian yang harus dimiliki berdasarkan bidang ilmu

d. Keahlian yang harus dimiliki berdasarkan kompetensi program studi

e. Keahlian yang harus dimiliki berdasarkan profesionalisme

7) Layanan untuk Alumni/Lulusan

a. Fasilitas dan layanan yang perlu dikembangkan untuk meningkatkan daya saing lulusan

b. Masukan apa yang perlu dilakukan universitas untuk membantu mendapatkan pekerjaan

Metode analisis data pada penelitian ini menggunakan analisis deskriptif persentase. Metode analisis deskriptif persentase digunakan untuk mendiskripsikan variabel studi penelusuran alumni JKG tahun 20102016. Variabel tersebut terdiri dari beberapa indikator yang sangat mendukung dan kemudian indikator tersebut dikembangkan menjadi instrumen (kuesioner). Menurut Muhammad Ali (1994) rumus yang digunakan dalam analisis deskriptif persentase adalah:

$$
\%=---\times 100 \%
$$

Keterangan:

$\%=$ Deskriptif Presentase dari studi penelusuran alumni

$\mathrm{n}=$ nilai diperoleh yaitu bobot masingmasing jawaban angket kali jumlah skor

$\mathrm{N}=$ jumlah seluruh nilai yaitu jumlah sampel kali jumlah item

Menurut Sugiyono (2009) statistik deskriptif adalah statistik yang digunakan 
untuk menganalisis data dengan cara mendeskripsikan atau menggambarkan data yang telah terkumpul sebagaimana adanya tanpa bermaksud membuat kesimpulan yang berlaku untuk umum atau generalisasi. Adapun langkah dan pembuatan kriteria persentase adalah:

a. Menentukan persentase maksimal dan persentase minimal

1) Persentase maksimal dicari dengan cara:

$$
\begin{aligned}
& =\frac{\text { skor maksmimal }}{\text { skor ideal }} \times 100 \% \\
& =\left(\frac{5}{5}\right) \times 100 \% \\
& =100 \%
\end{aligned}
$$

2) Persentase minimal dicari dengan cara:

$$
\begin{aligned}
& =\frac{\text { skor maksmimal }}{\text { skor ideal }} \times 100 \% \\
& =\left(\frac{1}{5}\right) \times 100 \% \\
& =20 \%
\end{aligned}
$$

b. Menentukan interval kelas dengan cara:

$$
\begin{aligned}
\text { Interval kelas } & =\frac{\% \text { tertinggi }-\% \text { terendah }}{\text { kelas yang dikehendaki }} \\
& =\frac{100 \%-20 \%}{5} \\
& =16 \%
\end{aligned}
$$

c. Menentukan banyaknya kriteria dibagi menjadi lima kriteria yaitu: sangat tinggi, tinggi, cukup, rendah, sangat rendah.

d. Selain itu juga mempertimbangkan beberapa kategori 
Tabel 4. Range variabel subyek penelitian

\begin{tabular}{|c|c|c|}
\hline $\begin{array}{c}\text { Sub } \\
\text { Variabel }\end{array}$ & Range & Kategori \\
\hline \multirow{4}{*}{$\begin{array}{c}\text { Lama masa } \\
\text { tunggu } \\
\text { (BAN-PT, } \\
\text { 2016) }\end{array}$} & $<3$ bulan & $\begin{array}{l}\text { SangatB } \\
\text { aik }\end{array}$ \\
\hline & 3-6 bulan & Baik \\
\hline & 6-12 bulan & Cukup \\
\hline & $>12$ bulan & Kurang \\
\hline \multirow{5}{*}{$\begin{array}{c}\text { TempatKer } \\
\text { jaatauInsta } \\
\text { nsitempatb } \\
\text { ekerja }\end{array}$} & $\begin{array}{l}\text { Instansipemerintah dan } \\
\text { RumahSakit }\end{array}$ & $\begin{array}{l}\text { Sangattin } \\
\text { ggi }\end{array}$ \\
\hline & $\begin{array}{l}\text { Klinik Gigi Bersama dan } \\
\text { Pribadi }\end{array}$ & Tinggi \\
\hline & PraktekMandiri & Cukup \\
\hline & $\begin{array}{l}\text { Bekerjatetapbukandibidan } \\
\text { gprofesi }\end{array}$ & Rendah \\
\hline & $\begin{array}{l}\text { Bekerjaparuhwaktubukand } \\
\text { ibidangprofesi }\end{array}$ & $\begin{array}{l}\text { SangatR } \\
\text { endah }\end{array}$ \\
\hline \multirow{5}{*}{$\begin{array}{c}\text { Rata-rata } \\
\text { penghasilan } \\
\text { atauGaji } \\
\text { (UMK } \\
\text { Jawa } \\
\text { Tengah } \\
\text { 2017 dan } \\
\text { GajiPokok } \\
\text { ASN 2017) }\end{array}$} & $>$ Rp.2.781.800,00 & $\begin{array}{l}\text { Sangattin } \\
\text { ggi }\end{array}$ \\
\hline & $\begin{array}{l}>\text { Rp.1.900.000,00- } \\
\text { Rp.2.781.800,00 }\end{array}$ & Tinggi \\
\hline & $\begin{array}{l}\text { >Rp.1.774.867,00- } \\
\text { Rp.1.900.000,00 }\end{array}$ & Cukup \\
\hline & $\begin{array}{l}>\text { Rp.1.570.000,00- } \\
\text { Rp.1.774.867,00 }\end{array}$ & Rendah \\
\hline & $<\operatorname{Rp} 1.370 .000$ & $\begin{array}{l}\text { SangatR } \\
\text { endah }\end{array}$ \\
\hline
\end{tabular}

e. Berdasarkan perhitungan di atas maka kriteria yang digunakan adalah:

Tabel 4.3 . Kriteria kategori hasil studi penelusuran alumni JKG Semarang

\begin{tabular}{|c|c|c|c|c|c|}
\hline No & $\begin{array}{c}\text { Interval } \\
\%\end{array}$ & $\begin{array}{c}\text { Kriteria } \\
\text { Lama } \\
\text { Waktu } \\
\text { Tunggu }\end{array}$ & $\begin{array}{c}\text { Kriteria Jenis } \\
\text { Pekerjaan yang } \\
\text { sesuai dengan } \\
\text { Kompetensi }\end{array}$ & $\begin{array}{c}\text { Kriteria } \\
\text { Tempat Kerja } \\
\text { atau Instansi }\end{array}$ & $\begin{array}{c}\text { Kriteria } \\
\text { Penghasilan }\end{array}$ \\
\hline 1. & $85 \%-100 \%$ & $\begin{array}{c}\text { Sangat } \\
\text { Tinggi }\end{array}$ & Sangat Tinggi & Sangat Tinggi & Sangat Tinggi \\
\hline 2. & $69 \%->84 \%$ & Tinggi & Tinggi & Tinggi & Tinggi \\
\hline 3. & $53 \% \cdot>68 \%$ & Cukup & Cukup & Cukup & Cukup \\
\hline 4. & $37 \%->52 \%$ & Rendah & Rendah & Rendah & Rendah \\
\hline 5. & $20 \%->36 \%$ & $\begin{array}{c}\text { Sangat } \\
\text { Rendah }\end{array}$ & Sangat Rendah & Sangat Rendah & $\begin{array}{c}\text { Sangat } \\
\text { Rendah }\end{array}$ \\
\hline
\end{tabular}

\section{HASIL DAN PEMBAHASAN}

Pemahaman alumni terhadap Visi Jurusan Keperawatan Gigi Poltekkes
Kemenkes Semarang 67\% menyatakan benar bahwa visi adalah Menjadi insitusi pendidikan yang mampu menghasilkan tenaga keperawatan gigi berbasis kearifan lokal yang unggul dan profesional diakui internasional tahun 2020. Namun yang yakin sekali hanya 59\% (80), lainya antara kurang yakin sampai ragu-ragu.

Pemahaman alumni terhadap Misi Jurusan Keperawatan Gigi Poltekkes Kemenkes Semarang 48\% menyatakan benar bahwa visi adalah Menjadi insitusi pendidikan yang mampu menghasilkan tenaga keperawatan gigi berbasis kearifan lokal yang unggul dan profesional diakui internasional tahun 2020. Namun yang yakin sekali hanya $31 \%$ (65), lainya antara kurang yakin sampai ragu-ragu.

Rata-rata lama waktu tunggu alumni Jurusan Keperawatan Gigi Poltekkes Kemenkes Semarang untuk bekerja adalah 59\% atau kriteria sangat baik. Sementara yang $>12$ bulan menunggu bekerja hanya 1,9\% .

Jenis pekerjaan alumni Jurusan Keperawatan Gigi Poltekkes Kemenkes Semarang $85 \%$ bekerja sebagai Terapis Gigi dan Mulut / Perawat Gigi. Bekerja tidak sesuai profesi hanya sebesar 3\% dan $6 \%$ masih sudah tidak bekerja karena menikah atau kuliah pasca sarjana.

Tempat kerja atau instansi tempat bekerja alumni Jurusan Keperawatan Gigi 
Poltekkes Kemenkes Semarang 52\% bekerja di Instansi pemerintah dan rumah sakit. Sedangkan yang bekerja di Klinik Gigi Bersama atau Pribadi sebanyak 29\%.

Rata-rata penghasilan atau gaji alumni dari tempat bekerja $78,7 \%$ dalam kategori rendah dan sangat rendah. Baru 7,3\% dengan kategori gaji sangat tinggi, 9,7\% dengan kategori tinggi, dan $4,3 \%$ mendapat gaji dengan kategori cukup.

Pemahaman alumni terhadap Visi dan Misi Jurusan Keperawatan Gigi Poltekkes Kemenkes Semarang meskipun banyak yang menyatakan benar kemungkinan karena mencermati target waktu pencapaian pada tahun 2020. Untuk memberikan pemahaman kepada alumni sebaiknya Visi Jurusan Keperawatan Gigi Poltekkes Kemenkes Semarang dapat disampaikan pada kegiatankegiatan lembaga atau pada saat seminar yang dihadiri alumni.

Rata-rata lama waktu tunggu alumni Jurusan Keperawatan Gigi Poltekkes Kemenkes Semarang untuk bekerja < dari 3 bulan karena para alumni Melalui iklan di koran/majalah, Melamar ke perusahaan tanpa mengetahui lowongan yang ada, Pergi ke bursa/pameran kerja, Mencari lewat internet/iklan online/milis, Dihubungi oleh perusahaan, Menghubungi agen tenaga kerja komersial/swasta, Memperoleh informasi dari pusat/kantor pengembangan karir fakultas/universitas, Membangun jejaring (network) sejak masih kuliah, Melalui relasi (misalnya dosen, orang tua, saudara, teman, dll.), Bekerja di tempat yang sama dengan tempat kerja semasa kuliah, lainnya.

Jenis pekerjaan alumni Jurusan Keperawatan Gigi Poltekkes Kemenkes Semarang $85 \%$ bekerja sebagai Terapis Gigi dan Mulut / Perawat Gigi. Hal ini dapat terjadi karena pada saat mengikuti perkuliahan mahasiswa merasakan metode yang digunakan berupa demonstrasi, keikutsertaan dalam suatu proyek, magang, praktek kerja lapangan, maupun diskusi sangat mendukung pada saat mereka menghadapi dunia kerja.

Tempat kerja atau instansi tempat bekerja alumni Jurusan Keperawatan Gigi Poltekkes Kemenkes Semarang di Instansi pemerintah dan rumah sakit cepat merespon lamaran (mengundang wawancara) alumni saat lulus karena metode pembelajaran yang digunakan berupa demonstrasi, keikutsertaan dalam suatu proyek, magang, praktek kerja lapangan, maupun diskusi sangat mendukung alumni menghadapi dunia kerja.

Rata-rata penghasilan atau gaji alumni dari tempat bekerja sebagian besar dalam kategori rendah dan sangat rendah karena jenis lembaga sebagaian besar adalah swasta. Untuk yang bekerja di Instansi pemerintah dan rumah sakit masih sedikit. 
Penilaian alumni terhadap kebutuhan kompetensi yang perlu di kuasai pada saat lulus adalah sebagai berikut :

1. Kebutuhan pengetahuan disiplin ilmu keperawatan gigi sebesar $75 \%$.

2. Kebutuhan kemampuan pengetahuan di luar disiplin ilmu keperawatan gigi sebesar $75 \%$.

3. Kebutuhan pengetahuan umum sebesar $74 \%$.

4. Kebutuhan berbahasa inggris dan internet sebesar $32 \%$.

5. Kebutuhan ketrampilan komputer sebesar $64 \%$.

6. Kebutuhan berpikir kritis sebesar $62 \%$.

7. Kebutuhan keterampilan riset sebesar $40 \%$.

8. Kebutuhan kemampuan belajar sebesar $73 \%$.

9. Kebutuhan kemampuan berkomunikasi sebesar $77 \%$.

10. Kebutuhan bekerja dibawah tekanan sebesar $36 \%$.

11. Kebutuhan manajemen waktu sebesar $62 \%$.

12. Kebutuhan bekrja secara mandiri sebesar $58 \%$.

13. Kebutuhan bekerja dalam tim/bekerjasama dengan orang lain sebesar $87 \%$.

14. Kebutuhan kemampuan dalam memecahkan masalah sebesar $64 \%$.
15. Kebutuhan negosiasi sebesar 54\%.

16. Kebutuhan kamampuan analisis sebesar $82 \%$.

17. Kebutuhan toleransi sebesar $83 \%$.

18. Kebutuhan kemampuan adaptasi sebesar $83 \%$.

19. Kebutuhan loyalitas sebesar $84 \%$.

20. Kebutuhan integritas sebesar $77 \%$.

21. Kebutuhan bekerja dengan orang yang berbeda budaya maupun latar belakang sebesar $72 \%$.

22. Kebutuhan kepemimpinan sebesar $56 \%$.

23. Kebutuhan kemampuan dalam memegang tanggungjawab sebesar $81 \%$.

24. Kebutuhan inisiatif sebesar $76 \%$.

25. Kebutuhan manajemen proyek/program sebesar $58 \%$.

26. Kebutuhan Kemampuan untuk mempresentasikan ide/produk/laporan sebesar $59 \%$

27. Kebutuhan kemampuan dalam menulis laporan, memo dan dokumen sebesar $69 \%$.

28. Kebutuhan kemampuan untuk terus belajar sepanjang hayat sebesar $79 \%$.

Penilaian alumni terhadap kebutuhan kompetensi yang perlu di kuasai saat bekerja adalah sebagai berikut :

1. Kebutuhan pengetahuan disiplin ilmu keperawatan gigi sebesar $90 \%$. 
2. Kebutuhan kemampuan pengetahuan di luar disiplin ilmu keperawatan gigi sebesar $66 \%$.

3. Kebutuhan pengetahuan umum sebesar $62 \%$.

4. Kebutuhan berbahasa inggris dan internet sebesar $43 \%$.

5. Kebutuhan ketrampilan komputer sebesar $79 \%$.

6. Kebutuhan berpikir kritis sebesar $74 \%$.

7. Kebutuhan keterampilan riset sebesar $58 \%$.

8. Kebutuhan kemampuan belajar sebesar $82 \%$.

9. Kebutuhan kemampuan berkomunikasi sebesar $85 \%$.

10. Kebutuhan bekerja dibawah tekanan sebesar $45 \%$.

11. Kebutuhan manajemen waktu sebesar $62 \%$.

12. Kebutuhan bekrja secara mandiri sebesar $66 \%$.

13. Kebutuhan bekerja dalam tim/bekerjasama dengan orang lain sebesar $82 \%$.

14. Kebutuhan kemampuan dalam memecahkan masalah sebesar $64 \%$.

15. Kebutuhan negosiasi sebesar $72 \%$.

16. Kebutuhan kamampuan analisis sebesar $67 \%$.

17. Kebutuhan toleransi sebesar $80 \%$.
18. Kebutuhan kemampuan adaptasi sebesar $81 \%$.

19. Kebutuhan loyalitas sebesar $82 \%$.

20. Kebutuhan integritas sebesar $77 \%$.

21. Kebutuhan bekerja dengan orang yang berbeda budaya maupun latar belakang sebesar $79 \%$.

22. Kebutuhan kepemimpinan sebesar $69 \%$.

23. Kebutuhan kemampuan dalam memegang tanggungjawab sebesar $86 \%$.

24. Kebutuhan inisiatif sebesar $80 \%$.

25. Kebutuhan manajemen proyek/program sebesar $64 \%$.

26. Kebutuhan Kemampuan untuk mempresentasikan ide/produk/laporan sebesar $68 \%$.

27. Kebutuhan kemampuan dalam menulis laporan, memo dan dokumen sebesar $78 \%$.

28. Kebutuhan kemampuan untuk terus belajar sepanjang hayat sebesar $81 \%$

\section{KESIMPULAN}

Pemahaman Visi Misi Jurusan Keperawatan Gigi Poltekkes Kemenkes Semarang perlu diberikan pemahaman kepada alumni pada kegiatan-kegiatan lembaga atau pada saat seminar yang dihadiri alumni.

Rata-rata lama waktu tunggu alumni Jurusan Keperawatan Gigi Poltekkes Kemenkes Semarang dalam mendapatkan pekerjaan pertama bagi wisudawan tahun 
2010-2016 yaitu kurang dari 3 bulan dengan persentase sebesar $59 \%$ dan yang menunggu $>12$ bulan dengan persentase sebesar 1,9\%. Jenis pekerjaan alumni yang sesuai dengan kompetensi lulusan Jurusan Keperawatan Gigi Poltekkes Kemenkes Semarang yaitu $85 \%$ bekerja terapis gigi dan mulut.

Tempat kerja atau instansi tempat bekerja alumni Jurusan Keperawatan Gigi Poltekkes Kemenkes Semarang 52\% bekerja di Instansi pemerintah dan rumah sakit. Sedangkan yang bekerja di Klinik Gigi Bersama atau Pribadi sebanyak 29\%. Ratarata penghasilan atau gaji alumni Jurusan Keperawatan Gigi Poltekkes Kemenkes Semarang yaitu rata-rata $78,7 \%$ dalam kategori rendah dan sangat rendah

\section{SARAN}

Setelah melakukan penelitian, penulis mencoba untuk memberikan beberapa saran :

1. Mempertahankan dan meningkatkan motivasi mahasiswa dengan memberikan informasi lowongan pekerjaan agar waktu tunggu tetap tinggi atau meningkat.

2. Pihak Jurusan Keperawatan Gigi Poltekkes Kemenkes Semarang untuk menyeimbangkan antara teori dan praktek serta kemajuan teknologi di lapangan agar mahasiswa mendapatkan pengalaman dalam menangani suatu pekerjaan.
3. Pihak Jurusan Keperawatan Gigi Poltekkes Kemenkes Semarang perlu meningkatkan kerjasama dengan pihak instansi negeri maupun instansi swasta untuk memudahkan alumni ataupun lulusan mencari dan mend 23 tkan pekerjaan serta memberikan informasi lowongan pekerjaan yang sesuai dengan kompetensi lulusan melalui unit karier.

4. Bagi mahasiswa diharapkan memberikan data berupa alamat rumah yang jelas dan lengkap serta nomor telepon atau handphone yang dapat dihubungi, untuk memudahkan pihak kampus melacak dan menelusuri mahasiswa ketika sudah lulus dengan cara melengkapi data pribadi di Sistem Akademik Terpadu Jurusan Keperawatan Gigi Poltekkes Kemenkes Semarang.

5. Pihak Jurusan Keperawatan Gigi Poltekkes Kemenkes Semarang sebaiknya rutin melakukan penelusuran terhadap alumni setiap 1-3 tahun sekali setelah mahasiswa lulus dari lembaga agar mengetahui pekermbangan masa transisi alumni dari dunia pendidikan tinggi ke dunia kerja.

6. Untuk penelitian mengenai studi penulusuran alumni selanjutnya sebaiknya menambahkan indikator demografi. 


\section{DAFTAR PUSTAKA}

Arikunto, S. 2006. Prosedur Penelitian Suatu Pendekatan Praktek. Jakarta : Rineka Cipta.

Azwar, S. 2007. Metode Penelitian. Yogyakarta : Pustaka Pelajar.

Badan Akreditasi Nasional Perguruan Tinggi. 2007. Buku V: Pedoman Penilaian Portofolio Akreditasi Institusi Perguruan Tinggi. Jakarta: Departemen Pendidikan Nasional, BAN-PT.

Hernawan, A.H. 2002. Prinsip-prinsip Pengembangan Kurikulum. Jakarta : Rineka Cipta.

Margono, S. 2007. Metodelogi Penelitian Pendidikan Komponen MKDK. Jakarta: PT. Rineka Cipta. 106

Mendiknas. 2003. Undang-undang Sistem Pendidikan Nasional Nomor 20 tahun 2003. Jakarta:
Mendiknas. . 2005. Undang-undang nomor 14 tahun 2005 tentang Guru dan Dosen. Jakarta: Mendiknas.

Nasution, S. 2003. Asas-asas Kurikulum. Jakarta : Bumi Aksara.

Nazir, M. 1999. Metode Penelitian. Jakarta : Ghalia Indonesia.

SEARCA. 2008. Tracer Study on SEARCA Fellows and UC Grantees. http://aau.org/studyprogram/web/schola rship. 24 Agustus 2008.

Setiawan, B., Muntaha, A. 2000. Metode Penelitian Komunikasi II. Jakarta : Pusat Penerbitan Universitas Terbuka.

Sudjana, N. 2005. Pembinaan dan Pengembangan Kurikulum di Sekolah. Bandung : Sinar Baru Algensindo.

Zembere, S.N., Chinyama, MPM. 2008. The University of Malawi Graduate Tracer Study

1996. http://aau.org/studyprogram/notpub. 24 Agustus 2008 